OPEN ACCESS

Edited by:

Yong Su,

Nanjing Agricultural University, China

Reviewed by:

Shunfen Zhang,

Chinese Academy of Agricultura

Sciences, China

Bao Yi,

Chinese Academy of Agricultural

Sciences (CAAS), China

${ }^{*}$ Correspondence:

Rui Li

lirui181000@163.com

Xingguo Huang

huangxi8379@aliyun.com

Specialty section:

This article was submitted to

Nutrition and Microbes,

a section of the journal

Frontiers in Nutrition

Received: 15 October 2020 Accepted: 16 November 2020

Published: 11 December 2020

Citation:

Hou G, Peng W, Wei L, Li R, Yuan Y,

Huang $X$ and $Y$ in $Y(2020)$

Lactobacillus delbrueckii Interfere With Bile Acid Enterohepatic Circulation to

Regulate Cholesterol Metabolism of Growing-Finishing Pigs via Its Bile Salt

Hydrolase Activity.

Front. Nutr. 7:617676.

doi: 10.3389/fnut.2020.617676

\section{Lactobacillus delbrueckii Interfere With Bile Acid Enterohepatic Circulation to Regulate Cholesterol Metabolism of Growing-Finishing Pigs via Its Bile Salt Hydrolase Activity}

\author{
Gaifeng Hou ${ }^{1,2}$, Wei Peng ${ }^{1,2}$, Liangkai Wei ${ }^{1,2}$, Rui $\mathrm{Li}^{1,2,3 *}$, Yong Yuan ${ }^{1,2}$, Xingguo Huang ${ }^{1,2 *}$ \\ and Yulong Yin ${ }^{1,2,3}$

\begin{abstract}
${ }^{1}$ College of Animal Science and Technology, Hunan Agricultural University, Changsha, China, ${ }^{2}$ Hunan Co-Innovation Center of Animal Production Safety, Changsha, China, ${ }^{3}$ Key Laboratory of Agro-ecological Processes in Subtropical Region, Scientific Observing and Experimental Station of Animal Nutrition and Feed Science in South-Central, Ministry of Agriculture, Hunan Provincial Engineering Research Center for Healthy Livestock and Poultry Production, Institute of Subtropical
\end{abstract} \\ Agriculture, Chinese Academy of Sciences, Changsha, China
}

Microbiota-targeted therapies for hypercholesterolemia get more and more attention and are recognized as an effective strategy for preventing and treating cardiovascular disease. The experiment was conducted to investigate the cholesterol-lowering mechanism of Lactobacillus delbrueckii in a pig model. Twelve barrows (38.70 $\pm 5.33 \mathrm{~kg})$ were randomly allocated to two groups and fed corn-soybean meal diets with either $0 \%$ (Con) or $0.1 \%$ Lactobacillus delbrueckii (Con + LD) for 28 days. L. delbrueckii-fed pigs had lower serum contents of total cholesterol (TC), total bile acids (TBAs), and triglyceride, but higher fecal TC and TBA excretion. L. delbrueckii treatment increased ileal Lactobacillus abundance and bile acid (BA) deconjugation and affected serum and hepatic BA composition. Dietary L. delbrueckii downregulated the gene expression of ileal apical sodium-dependent bile acid transporter (ASBT) and ileal bile acid binding protein (IBABP), and hepatic farnesoid $X$ receptor (FXR), fibroblast growth factor (FGF19), and small heterodimer partner $(S H P)$, but upregulated hepatic high-density lipoprotein receptor $(H D L R)$, low-density lipoprotein receptor $(L D L R)$, sterol regulatory element binding protein-2 (SREBP-2), and cholesterol-7 $\alpha$ hydroxylase (CYP7A1) expression. Our results provided in vivo evidence that $L$. delbrueckii promote ileal BA deconjugation with subsequent fecal TC and TBA extraction by modifying ileal microbiota composition and induce hepatic BA neosynthesis via regulating gut-liver FXR-FGF19 axis.

Keywords: Lactobacillus delbrueckii, ileal microbiota, cholesterol, bile acids, enterohepatic circulation, pigs 


\section{INTRODUCTION}

Cholesterol is an indispensable fundamental building block for all cell membranes, but long-term high level of blood cholesterol may induce hypercholesterolemia-associated cardiovascular diseases (CVDs), a major contributing factor of adult deaths worldwide $(1,2)$. It is reported that a $1 \%$ reduction in blood cholesterol translates to a $2 \%$ decrease in heart disease risk $(3,4)$. Blood cholesterol level is determined by dietary fat and cholesterol intake and the body's cholesterol biosynthesis and excretion (5). Endogenous synthetic cholesterol accounts for nearly $70 \%$, whereas the remaining $30 \%$ amount is mainly derived from animal products (6). Pork products are rich in cholesterol ranging from $57 \mathrm{mg} / 100 \mathrm{~g}$ in loin to $116 \mathrm{mg} / 100 \mathrm{~g}$ in dewlap (7). In China, pork is the most popular animal meat, and its production and consumption contribute about $50 \%$ of global pork output ranking first in the world (8). Therefore, clarification of underlying mechanisms of cholesterol metabolism in pigs and development of low cholesterol pork products has a promising potential of scientific researches and consumer markets.

Cholesterol is a precursor to bile acid (BA) biosynthesis. Approximately $30 \%$ to $40 \%$ of cholesterol is converted into primary BAs in liver via two pathways, with CYP7A1 as the rate-limiting enzyme in the classic pathway and CYP7B1 as an important enzyme in the alternative pathway $(9,10)$. Synthesized primary BAs are conjugated either with taurine or glycine and temporarily stored in the gallbladder. Upon cholecystokinin stimulation, often as a result of a meal, BAs are released into the duodenum via the bile duct. About $95 \%$ of BAs are reabsorbed all along the intestine, especially in the distal ileum, via passive diffusion and carrier-mediated transports entering enterohepatic cycle to maintain the BA pool homeostasis $(11,12)$. In each cycle, nearly $4 \%$ BAs are excreted along with feces, which is offset by the hepatic de novo synthesis of BAs from cholesterol (12). Obviously, the conversion of cholesterol to the BAs is the major route for cholesterol excretion, and the increased fecal BA excretion favors the conversion from cholesterol to BAs and reduces its release into the systemic circulation (13).

The hypocholesterolemic effect of Lactobacillus or its related products are reported extensively in animals and clinical researches $(4,12,14,15)$. Several proposed potential cholesterollowering mechanisms of Lactobacillus products chiefly cover cholesterol assimilation, cholesterol conversion to coprostanol, $\mathrm{BSH}$ activity, production of short fatty acids, and regulation of key enzyme in cholesterol metabolism $(3,12)$. However, the majority of explanations were based on in vitro test or high-fat or cholesterol animal models, and there was no adequate supporting evidence from normal subjects to validate these assumptions. Interestingly, our prior work confirmed that dietary Lactobacillus delbrueckii $\left[1.01 \times 10^{9}\right.$ colony-forming units $\left.(\mathrm{CFU}) / \mathrm{g}\right]$ lowered serum TC and triglyceride (TG) and increased the fecal TC and total BA (TBA) excretion of fatten pigs in commercial condition; unfortunately, we did not explore the further mechanism (16).

Given that the close relationship between cholesterol and BA metabolism, we supposed that L. delbrueckii with BSH activity affected the enterohepatic circulation of BA, which contributed to the reduced serum TC in a pig model. Therefore, we investigated the BSH activity of L. delbrueckii through plate assay and gene identification and also evaluated the effects of $L$. delbrueckii on intestinal microbiota, BA and cholesterol metabolism, and tissue lipids of growing-finishing pigs.

\section{MATERIALS AND METHODS}

All protocols and procedures involved in the experiment were approved by the Animal Ethics Committee of Hunan Agricultural University (Changsha, China). L. delbrueckii was provided by the microbiology functional laboratory of the College of Animal Science and Technology in the Hunan Agricultural University (Changsha, China). The strain was activated and sent to the PERFLY-BIO (Changsha, China) for large-scale production, and the viable count of final products reached $5 \times 10^{11} \mathrm{CFU} / \mathrm{g}$.

\section{Animals and Experimental Design}

Twelve Landrace $\times$ Yorkshire crossbred barrows with an average initial body weight of $38.70 \pm 5.33 \mathrm{~kg}$ were randomly allocated to two groups, and each group had six pigs individually housed in the metabolism cage. Pigs were fed with corn-soybean meal diets (basal diets, Con) or basal diets containing $0.1 \% L$. delbrueckii preparation $\left(5 \times 10^{10} \mathrm{CFU} / \mathrm{g}\right.$, Con $\left.+\mathrm{LD}\right)$ for 28 days. The basal diets (Table 1) were formulated to meet the nutritional requirement of 50 - to $75-\mathrm{kg}$ pigs recommended by the NRC 2012 (17). All pigs were fed twice each day (8:00 A.M. and 3:00 P.M.) and had free access to water. The body weight of each pig was weighed at the beginning and end of the experiment, and the daily feed consumption per pig was recorded during the experimental period. Fecal samples were collected, freeze-dried, and stored at $-20^{\circ} \mathrm{C}$ for total cholesterol (TC) and TBA detection. On day 29, the jugular vein blood samples were collected from the fasting pigs before slaughter using electrical stunning. Serum was obtained, aliquoted, and stored at $-20^{\circ} \mathrm{C}$ for lipid analysis and BA profiles quantification. Digesta (in ileum) and tissues (in ileum, liver, longissimus dorsi, subcutaneous fat, and leaf lard) were quickly removed, snapfrozen in the liquid nitrogen, and stored at $-80^{\circ} \mathrm{C}$ for microbiota composition, BA quantification, gene mRNA expression, lipid profile, and enzyme activity measurements.

\section{Qualitative Determination of BSH Activity}

Qualitative BSH activity of $L$. delbrueckii was measured according to the method introduced by Jayashree et al. (18) and Guo et al. (19) with a minor modification. Briefly, five sterile paper discs (8-mm diameter) were placed on an MRS agar plate containing $2 \mathrm{~g} / \mathrm{L}$ taurodeoxycholate and glycodeoxycholate, $2 \mathrm{~g} / \mathrm{L}$ sodium thioglycolate and $0.37 \mathrm{~g} / \mathrm{L} \mathrm{CaCl}_{2}$, and $100 \mu \mathrm{L} \mathrm{L}$. delbrueckii solution ( $1 \mathrm{~g}$ bacterial power was diluted with $9 \mathrm{~mL}$ of sterile water to get final concentrations of $1.5 \times 10^{10} \mathrm{CFU} / \mathrm{mL}$ ) were added to the paper discs immediately. The plates were incubated at $37^{\circ} \mathrm{C}$ for $72 \mathrm{~h}$. The BA precipitates (i.e., opaque granular white colonies with silvery shine) around the discs were considered as BSH activity.

Genomic DNA of the L. delbrueckii was extracted using the TIANamp Stool DNA kit [Tiangen Biotech (Beijing) Co., Ltd, 
TABLE 1 | Diet composition and nutritional levels of basal diets (air-dry basis, \%).

\begin{tabular}{lc}
\hline Ingredients & Contents \\
\hline Corn & 66.76 \\
Wheat middling & 4.00 \\
Wheat bran & 6.00 \\
Soybean meal (43\% crude protein) & 18.00 \\
Soybean oil & 1.00 \\
L-Lysine & 0.24 \\
Premix & 4.00 \\
Total & 100.00 \\
Calculated nutritional levels & \\
Digestible energy (DE, kcal/kg) & $3,413.79$ \\
Crude protein & 14.82 \\
Standardized ileal digestible lysine (SID Lys) & 0.85 \\
Calcium & 0.60 \\
Total phosphorus & 0.55 \\
\hline aThe premix provided the following per $\mathrm{kg}$ of diet:VA2 512 IU, VD3 1 200 IU, VE 34 IU, \\
VK3 1.5 mg, VB12 17.6 $\mu$ g, lactoflavin 2.0.5 mg, pantothenic acid 6.8 mg, niacin 20.3 mg, \\
choline chloride 351, Mn 10 mg, Fe 50 mg, Zn 50 mg, CU 20 mg, I 0.3 mg, Se 0.3 mg.
\end{tabular}

China]. According to the report by Jayashree et al. (18), two primers (Table 2) for $\mathrm{BSH} 1$ and $\mathrm{BSH} 2$ were used to amplify the corresponding target gene, and the polymerase chain reaction (PCR) product sizes were 927 and 978 bp, respectively. The PCR reactions were carried out in $25-\mu \mathrm{L}$ reaction system in a TaKaRa PCR Thermal Cycler. The PCR conditions were $5 \mathrm{~min}$ at $94^{\circ} \mathrm{C}$ for the initial denaturation followed by 35 cycles of denaturation at $94^{\circ} \mathrm{C}$ for $30 \mathrm{~s}, 1 \mathrm{~min}$ at $52^{\circ} \mathrm{C}$ for annealing, $1 \mathrm{~min}$ at $72^{\circ} \mathrm{C}$ for extension, and $5 \mathrm{~min}$ at $72^{\circ} \mathrm{C}$ for the final extension.

\section{Determination of Serum and Tissue Lipids}

Fasting blood of pigs were collected and placed at room temperature for $30 \mathrm{~min}$, and the serum were separated by centrifugation $\left(3,000\right.$ revolutions $/ \mathrm{min}$ for $10 \mathrm{~min}$ at $\left.4^{\circ} \mathrm{C}\right)$. Serum concentrations of TG, glucose (GLU), TBA, TC, high-density lipoprotein cholesterol (HDL-C), and high-density lipoprotein cholesterol (LDL-C) were measured by the BS 200 automatic blood biochemical analyzer (Mindray) with corresponding kits.

The total protein contents $(g$ protein/L) in tissues were quantified using a BCA protein assay reagent kits (Nanjing Jiancheng Bioengineering Institute, Nanjing, China). About $100 \mathrm{mg}$ of liver, longissimus dorsi, subcutaneous fat, or leaf lard was homogenized with $1 \mathrm{~mL}$ of chloroform/methannol solution $(2: 1, \mathrm{vol} / \mathrm{vol})$, respectively. The homogenate were centrifuged at 3,000 revolutions/min for $10 \mathrm{~min}$ at $4^{\circ} \mathrm{C}$ to extract tissue lipids. The contents of TC $(\mathrm{mmol} / \mathrm{g} \cdot$ protein), TG $(\mathrm{mmol} / \mathrm{g}$. protein), and TBA ( $\mu \mathrm{mol} / \mathrm{g} \cdot$ protein) in the selected tissue were measured by corresponding commercial kits (Nanjing Jianchen Bioengineering Institute, Jiangsu, China).

\section{Measurement of Hepatic Enzyme Activity Using ELISA Kits}

Hepatic total protein contents (g protein/L) were measured as described above, and the concentrations of hepatic 3hydroxy-3-methyl glutaryl coenzyme A reductase (HMGR, U/g .
TABLE 2 | Primers used in the study.

\begin{tabular}{|c|c|c|}
\hline Items & Gene & Sequence $\left(5^{\prime}-3^{\prime}\right)$ \\
\hline \multirow[t]{4}{*}{ BSH gene } & BSH1 & F: GCCACCATGGTAATGTGCACGGCCGTTCC \\
\hline & & R: CGATGGATCCTTAGGGTACTTGCGATAGG \\
\hline & $\mathrm{BSH} 2$ & F:ACCCATGGGTATGTGCACGAGCATCAACGTCA \\
\hline & & R: AAGGATCCGTTCAATTTCACCGGCGCCCAA \\
\hline \multirow{6}{*}{$\begin{array}{l}\text { BA receptor and } \\
\text { signaling }\end{array}$} & FXR & F: GGTCCTCGTAGAATTCACAA \\
\hline & & R: TGAACGGAGAAACATAGCTT \\
\hline & FGF19 & AGTACTCGGATGAGGACTGTGCTT \\
\hline & & AGAGACGGGCAGATGGTGTTCTT \\
\hline & SHP & F: GCCTACCTGAAAGGGACCAT \\
\hline & & R: CAACGGGTGTCAAGCCTTA \\
\hline \multirow[t]{4}{*}{ BA transport } & ASBT & F: TACGCGGTATACAGGAAATGGTA \\
\hline & & R: TITGCCTITGGAATGATGACT \\
\hline & $I B A B P$ & F: GTGAACAGCCCCAACTACCACCA \\
\hline & & R: TCGTAGCTCACGCCTCCGAC \\
\hline \multirow[t]{4}{*}{ BA biosynthesis } & CYP7A1 & F: GAAAGAGAGACCACATCTCGG \\
\hline & & R: GAATGGTGTTGGCTTGCGAT \\
\hline & CYP27A1 & F: ACTGAAGACCGCGATGAAAC \\
\hline & & R: CAAAGGCGAATCAGGAAGGG \\
\hline
\end{tabular}

Cholesterol SREBP- F: GATGGGCAGCAGAGTTCC biosynthesis and 2

transport

\section{R: ACAGCAGCAGGTCACAGGT}

HMGR F: ATGGCATGACTCCAGTGGTACGTT R: GCAAATCTGCTGGTGCTGTCGAAT

HDLR F: CACTATGCCCAGTACGTGCTC

R: CCTGAATGGCCTCCTTATCCTT

LDLR F: TTCTTCACCAACCGCCACGAG

R: CTCAGTGTCCAGAGCGACC

Housekeeping GAPDH F: ATGGTGAAGGTCGGAGTGAAC gene

\section{R: CTCGCTCCTGGAAGATGGT}

BSH, bile salt hydrolase; FXR, farnesoid $X$ receptor; FGF19, fibroblast growth factor; SHP, small heterodimer partner; ASBT, apical sodium-dependent bile acid transporter; IBABP, ileal bile acid binding protein; CYP7A1, Cholesterol-7a hydroxylase; CYP27A1, cholesterol-27a hydroxylase; SREBP-2, sterol regulatory element binding protein2; HMGR, 3-hydroxy-3-methyl glutaryl coenzyme A reductase; HDLR, high-density lipoprotein receptor; $L D L R$, low-density lipoprotein receptor.

protein) and cholesterol-7 $\alpha$ hydroxylase (CYP7A1, U/g · protein) were measured following the instruction of corresponding commercial ELISA Kits (Jiangsu Yutong Biological Technology Co., Ltd., Jiangsu).

\section{Fecal TC and TBA Excretion}

Fecal lipids were extracted as described above for TC analysis. Fecal TBA was extracted according to the method by De Smet et al. (5). Briefly, $1 \mathrm{~g}$ frozen fecal sample was dissolved in $40 \mathrm{~mL}$ methanol. After 4-min sonication and 1-h shock, the mixture was centrifuged at $10,000 \mathrm{~g}$ for $10 \mathrm{~min}$ to collect the supernatants. Total TC $(\mathrm{mmol} / \mathrm{L})$ and TBA $(\mu \mathrm{mol} / \mathrm{L})$ concentrations in the supernatants were determined using a commercial kit purchased from the Nanjing Jianchen Bioengineering Institute. 
At last, fecal TC and TBA contents (mg/g) were obtained by formula conversion.

\section{BA Profile Analysis \\ Metabolite Extraction}

About $30 \mathrm{mg}$ of solid samples (ileal digesta or hepatic tissue) were homogenized in $100 \mu \mathrm{L}$ of precooled ultrapure water, vortexed with 5,000 $\mu \mathrm{L}$ of iced methanol and $10 \mu \mathrm{L}$ of internal standard solution (for liquid sample, $100 \mu \mathrm{L}$ serum was directly vortexed with $500 \mu \mathrm{L}$ of iced methanol and $10 \mu \mathrm{L}$ of internal standard solution), incubated at $-20^{\circ} \mathrm{C}$ for $20 \mathrm{~min}$ for depositing protein, and centrifuged at 14,000 relative centrifugal force $(\mathrm{rcf}) / \mathrm{min}$ for $15 \mathrm{~min}$ at $4^{\circ} \mathrm{C}$. The supernatants were vacuum dried for subsequent analysis.

\section{Ultraperformance Liquid Chromatography-Mass Spectrometry (UPLC-MS) Analysis}

BA profiles were analyzed with a Waters ACQUITY UPLC IClass coupled with a 5500 QTRAP mass spectrometer with an ESI source (Waters, Milford, MA). Briefly, the samples above were resolved in 1:1 ( vol/vol) methanol solution and centrifuged at $14,000 \mathrm{rcf} / \mathrm{min}$ for $15 \mathrm{~min}$ at $4^{\circ} \mathrm{C}$ to obtain supernatants. The supernatants were separated using an ACQUITY UPLC BEH C18 chromatographic column $(1.7 \mu \mathrm{m}, 100 \times 2.1 \mathrm{~mm})$ (Waters, Milford, MA), and column temperature reached $50^{\circ} \mathrm{C}$. The injection volume was $2 \mu \mathrm{L}$. A mobile phase system included Solvent A (0.1\% FA solution) and Solvent B (methanol), in a gradient system at a flow rate of $0.3 \mathrm{~mL} / \mathrm{min}$. The mobile phase $B$ was linearly changed as follows: from 60 to $65 \%$ (0-6 min), 65 to $80 \%$ (6-13 $\mathrm{min}$ ), 65 to $80 \%$ (6-13 $\mathrm{min}$ ), 80 to $90 \%$ (13-13.5 $\mathrm{min}$ ), and stabilization at $90 \%(13.5-15 \mathrm{~min})$. The mass spectrometer was used in Multiple Reaction Monitoring function in the ESInegative mode to achieve information of tested ion pairs. The operating parameters were as follows: source temperature $550^{\circ} \mathrm{C}$; ion source gas $155 \mathrm{psi}$; ion source gas $155 \mathrm{psi}$; curtain gas 40 psi; and IonSapary voltage floating $-4,500 \mathrm{~V}$. UPLC-MS raw data were analyzed using Multiquant ${ }^{\mathrm{TM}}$ software (v. 2.1) to obtain calibration equations and the quantitative concentrations of each BA.

\section{Ileal Microbiota Analysis}

Microbiota composition was analyzed according to our previous study $(20,21)$. Briefly, the ileal digesta were collected, frozen in liquid nitrogen, and stored at $-80^{\circ} \mathrm{C}$ for further analysis. Total DNA was extracted and purified from digesta samples ( $n=5$ pigs/group) using TIANamp Stool DNA kit [Tiangen Biotech (Beijing) Co., Ltd, China]. DNA quality and quantity were evaluated by gel electrophoresis and a NanoDrop ND-1000 spectrophotometer (Thermo Fisher Scientific, USA), respectively. Ten acceptable DNA samples were delivered to Novogene (Beijing) for $16 \mathrm{~S}$ rDNA sequencing.

The V3-V4 hypervariable region of the bacterial 16S rDNA gene was amplified with the barcoded universal primers (341F806R). Purified amplicons were sequenced on the Illumina HiSeq platform (Illumina, USA) according to the standard procedures in Novogene (Beijing). Sequences with $97 \%$ similarity were assigned to the same operational taxonomic units (OTUs). An OTU table was further generated to record the abundance of each OTU in each sample, and a profiling histogram was made using R software (v. 3.1.1) to represent the relative abundance of taxonomic groups from phylum to species. A Venn diagram was generated to visualize the occurrence of shared and unique OTUs among groups.

\section{Real-Time PCR}

Total RNA of ileal or hepatic tissue was isolated and reversed transcribed to cDNA as previously described $(20,21)$. The two-step qRT-PCR reactions were performed in triplicate on 96-well plates using a 7500 Real-time PCR system (Applied Biosystems, Foster, CA) with the SYBR Premix Ex Taq ${ }^{\mathrm{TM}}$ (TaKaRa Biotechnology (Dalian), China). The primer sequences (Table 2) of farnesoid $\mathrm{X}$ receptor $(F X R)$, fibroblast growth factor (FGF19), SHP, ASBT, IBABP, CYP7A1, cholesterol$27 \alpha$ hydroxylase (CYP27A1), sterol regulatory element binding protein-2 (SREBP-2), HMGR, high-density lipoprotein receptor $(H D L R)$, low-density lipoprotein receptor $(L D L R)$ and $G A P D H$ were synthesized by the Sangon Biotech (Shanghai, China). Target gene expression was calculated by the $2^{-\Delta \Delta \mathrm{t}}$ method relative to GAPDH gene amplification.

\section{Statistical Analysis}

All results were expressed as mean $\pm \mathrm{SD}$. Statistical analyses, except for microbiota data, were conducted by the two-tailed unpaired Student $t$-test of SPSS 17.0 (SPSS Inc., Chicago, IL, USA), with individual pig as an experimental unit. The Kruskal test was used for post hoc comparison of taxonomy. For all tests, $P<0.05$ was considered as significant difference, while $0.05<P$ $<0.10$ as a tendency.

\section{RESULTS}

\section{Qualitative Identification of BSH Activity}

After incubation for $12 \mathrm{~h}$, non-obvious BA precipitates appeared around the discs in the plate (Figure 1A); however, the opaque granular white colonies with silvery shine were observed after 72$\mathrm{h}$ incubation (Figure 1B). PCR amplification of two designated genes showed that the BSH2 gene was identified, not BSH1, on the genome sequence of $L$. delbrueckii (Figure 1C).

\section{Serum Lipid Profiles}

Serum TC, TBA, and TG contents in L. delbrueckii-fed pigs were found to be lower than the pigs in the Con group $(P<0.05$; Figures 2A,C,D). L. delbrueckii treatment tended to reduce the concentration of serum LDL-C $(P=0.075)$ and elevate serum HDL-C $(P=0.093)$ level (Figure 2A). No significant changes in serum GLU and HDL-C/LDL$\mathrm{C}$ contents were observed between two groups $(P>0.05$, Figures 2B,E).

\section{Alterations in BA Profiles of Serum, lleal Digesta, and Liver}

Compared with the Con group, lower serum levels of CDCA, HCA, GCA, GCDCA, GHDCA, TUDCA, THDCA, primary 

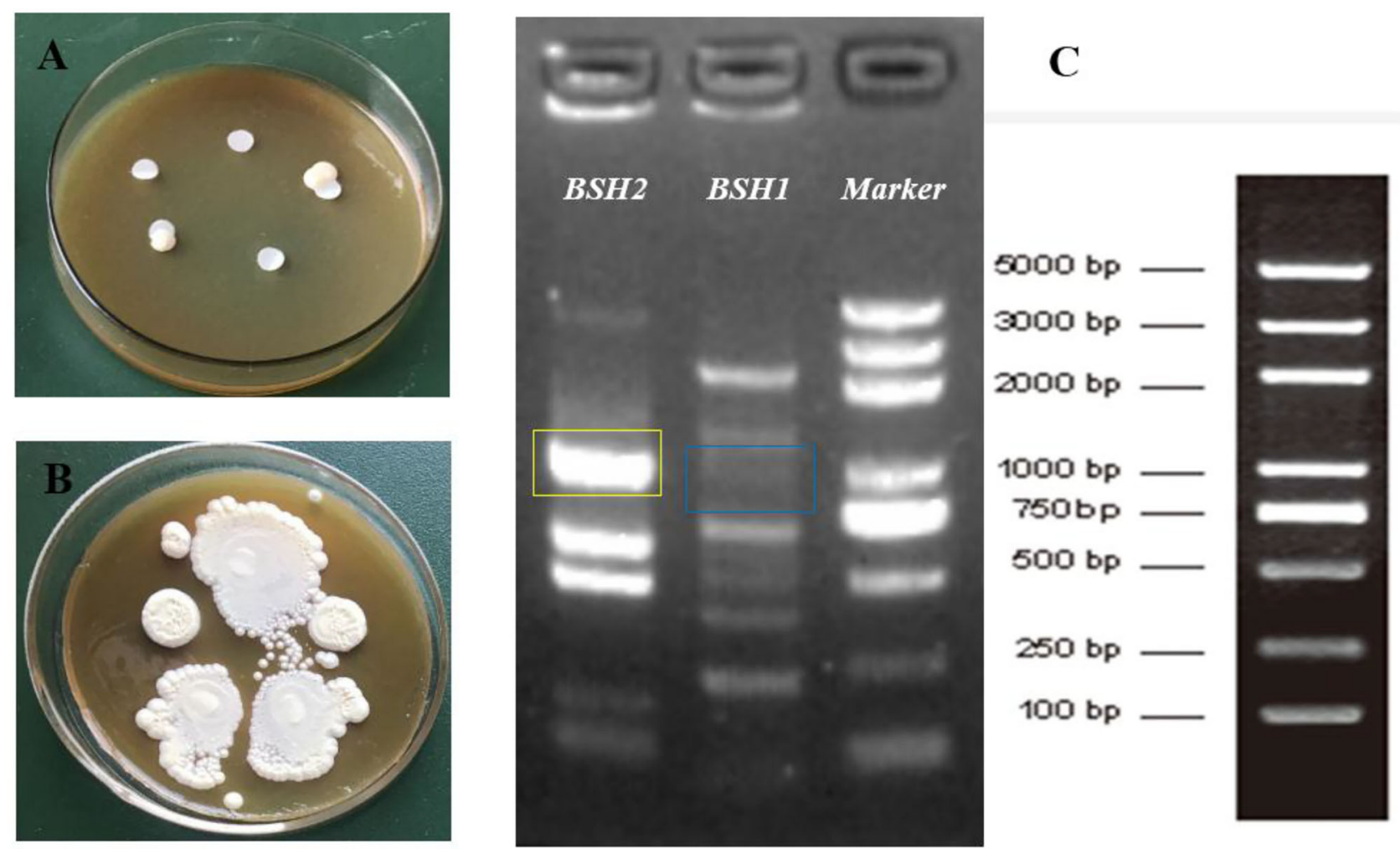

FIGURE 1 | Identification of bile salt hydrolase (BSH) activity in Lactobacillus delbrueckii. Incubation on MRS plate containing bile salts for $12 \mathrm{~h}$ (A) and $72 \mathrm{~h}$ (B), respectively. Amplification of $\mathrm{BSH}$ genes in L. delbrueckii $\mathbf{( C )}$ and target band sites for $B S H 1$ and $B S H 2$ gene were marked with blue and yellow box, respectively.

$\mathrm{BA}$, secondary $\mathrm{BA}$, unconjugated $\mathrm{BA}$, and total $\mathrm{BA}$ were found in the Con-LD group $(P<0.05$, Figure 3A). Dietary addition of $L$. delbrueckii increased the ileal concentrations of $\mathrm{CA}$ and unconjugated BA $(P=0.085)$, but reduced GCDCA and GLCA $(P<0.05$, Figure 3B). Hepatic concentrations of DCA $(P=0.052)$, HDCA, TCDCA, TUDCA, THDCA, and secondary $\mathrm{BA}(P=0.094)$ in $L$. delbrueckii-fed pigs were decreased compared to the pigs in the Con group $(P<0.05$, Figure 3C).

\section{Ileal Bacteria Composition}

The Venn picture presented 546 shared OTUs between two groups, and there were 219 and 153 unique OTUs in the Con and Con + LD group, respectively (Figure 4A). The bacterial population was dominated by Firmicutes and Proteobacteria, with minor populations such as Actinobacteria and Bacteroidetes (Figure 4B). Administration of $L$. delbrueckii increased the abundance of Actinobacteria $(P=0.071)$, Spirochaetes $(P=$ $0.070)$, and Kiritimatiellaeota $(P=0.029)$ and reduced the abundance of Melainabacteria $(P=0.091)$ and Elusimicrobia $(P=0.029)$. Down to the genus level, the higher abundance of Lactobacillus $(P=0.002)$ and lower abundance of Clostridiales $(P=0.031)$, Ruminococcaceae $(P=0.061)$, Enterococcus $(P=$ $0.035)$, Streptococcus $(P=0.052)$, and Rothia $(P=0.049)$ were found (Figure 4C and Supplementary Table 1).

\section{BA and Cholesterol Transport, Biosynthesis, and Excretion}

Administration of $L$. delbrueckii downregulated the gene expression of ileal FGF19 ( $P=0.089)$, ASBT, and IBABP and enhanced fecal TC and TBA excretion $(P<0.05$, Figures 5A,B). Hepatic gene expressions of FXR, FGF19, and SHP were reduced, but HDLR, LDLR, SREBP-2, and CYP7A1 were increased in the Con + LD group $(P<0.05$, Figure $5 C)$. Hepatic CYP7A1 activity tended to be greater in the $L$. delbrueckii-fed pigs than those in the Con group $(P=0.062$, Figure 5D). No changes were found in hepatic concentrations of TC, TG, and TBA between two groups $(P>0.05$, Figures 5E,F).

\section{Tissue TG and TC Deposition}

The concentrations of TG and TC in the longissimus dorsi, subcutaneous fat, and leaf lard had no differences between two groups $(P>0.05$, Figure 6).

\section{DISCUSSION}

Fluctuation of blood lipids parameters can reflect the body's lipid metabolism and health status; chronically high serum TC and LDL-C levels are strongly associated with the increased risks of $\operatorname{CVD}(22,23)$. TC and TG are the main components of blood lipids; lowering their concentrations can prevent hyperlipemia. Considerable researches have confirmed that 


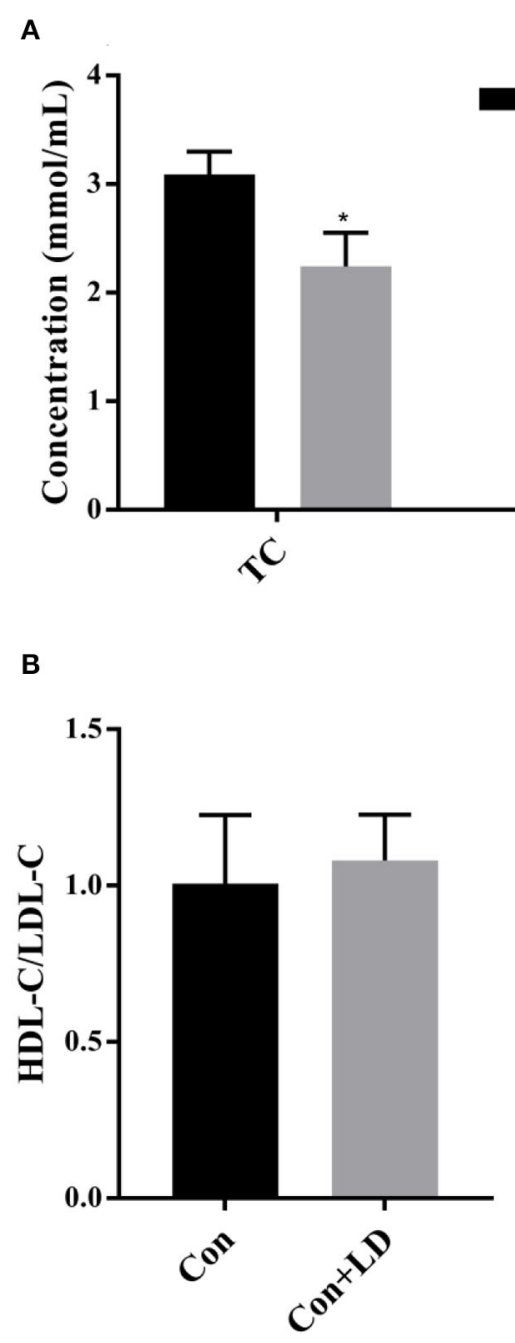

\section{Con+LD}

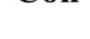

Cont 
A

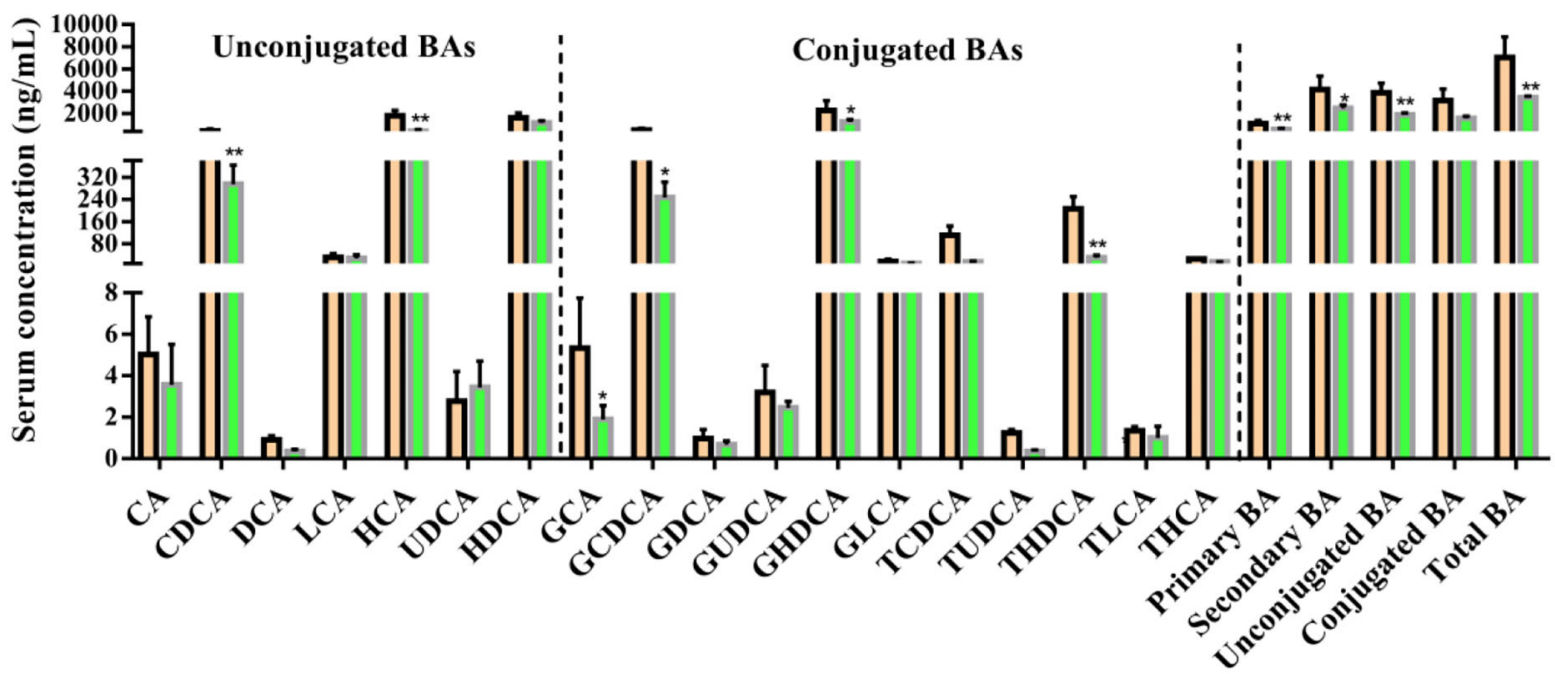

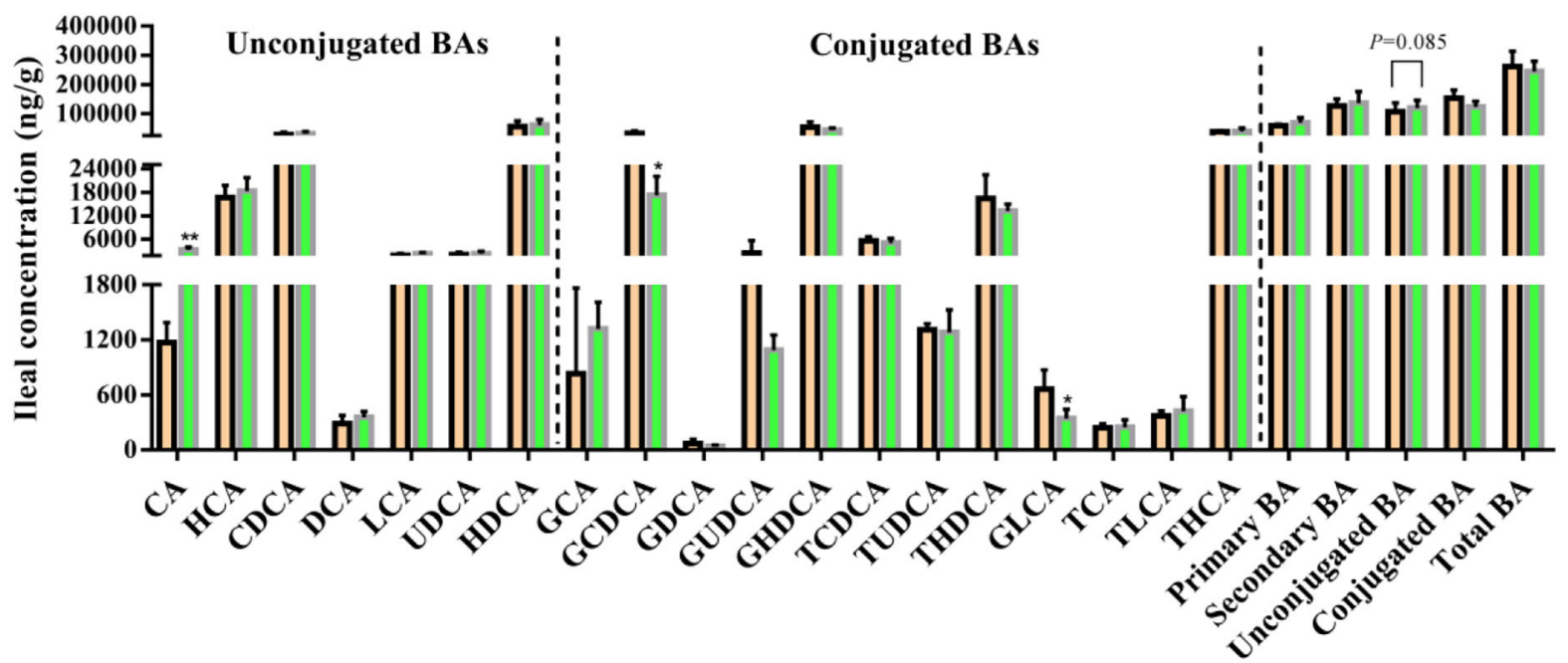

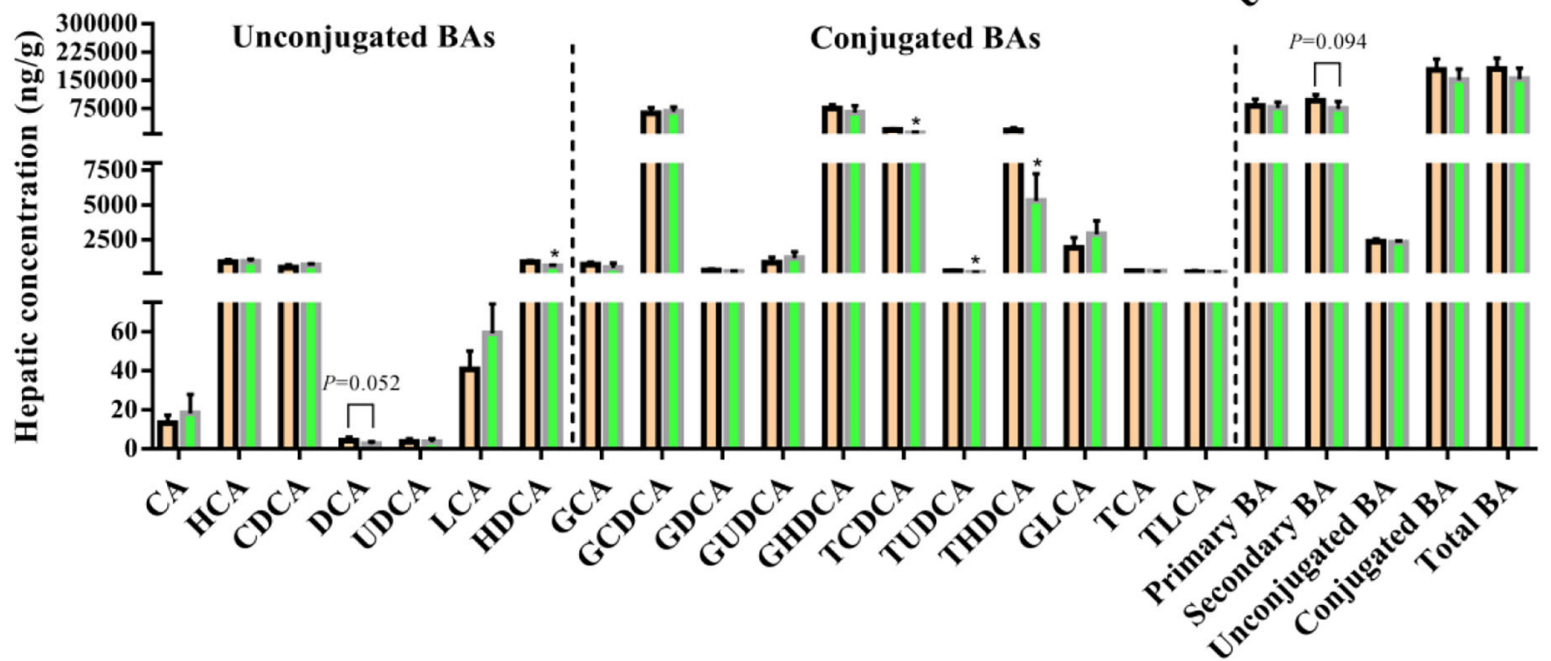

FIGURE 3 | Bile acids profile in the serum (A), ileal digesta (B), and liver (C) of growing-finishing pigs $\left({ }^{\star} P<0.05 ;{ }^{\star \star} P<0.01\right)$. 
A

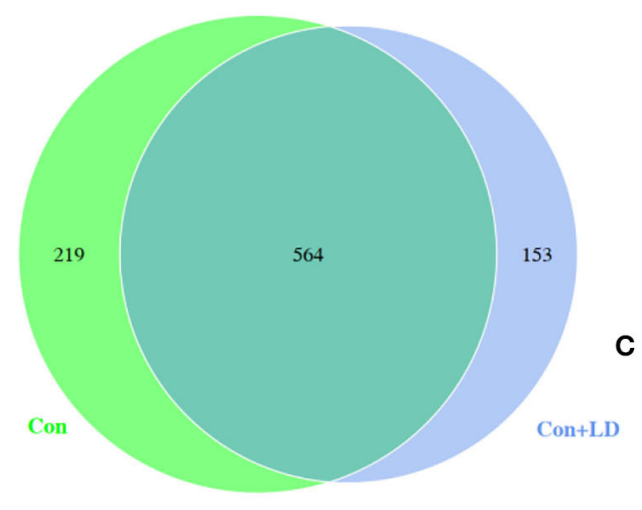

B
Phylum level

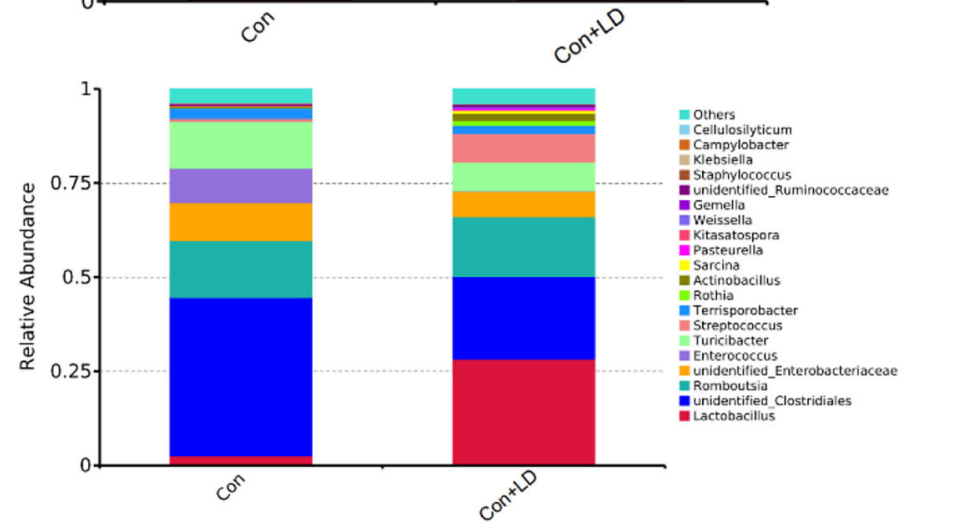

FIGURE 4 | lleal bacterial composition of growing-finishing pigs. Venn picture showed shared or unique OTUs between two groups (A). Relative abundance of ileal microbiota at the phylum (B) or genus (C) level.

consumption of Lactobacillus products reduced concentrations of serum cholesterol and improved lipid profiles (24-26). In the current study, dietary addition of $L$. delbrueckii decreased serum levels of TC, LDL-C, and TG of pigs. Our findings were again the proof of our previous reports (16) and also offered another evidence for cholesterol-lowering role of lactic acid bacteria in normal subject. The hypocholesterolemic effect of $L$. delbrueckii might provide a potential dietary manipulation way to prevent and improve hyperlipidemia.

Probiotics with BSH activity is hypothesized to be an important character in lowering serum cholesterol, which might be tightly related to the BSH genes on their genome $(1,4,12$, $22,27)$. BSH activity has been characterized in Lactobacillus, Bifidobacterium, Clostridium, Enterococcus, and Bacteroides (12). L. delbrueckii tested in this study possessed the $\mathrm{BSH} 2$ gene identified by PCR amplification and exhibited a good BSH activity on the modified agar plate, demonstrating the strain was capable of bile salts deconjugation. BSH enzyme or activity is specific to the microbiota and is not present in eukaryotic cells, which is regarded as a crucial probiotic marker that help organisms resist toxic bile salt environment in the digestive tract and also an important colonization factor for gut bacteria $(12,28)$. Lactobacillus with BSH activity contribute to their survival and colonization in the gastrointestinal tract and exert a beneficial effect on host by regulating cholesterol and BA enterohepatic circulation $(1,4,15,29)$. Our results suggest that L. delbrueckii might own a good ability of intestinal survival and colonization and play a key role in regulating cholesterol and BA metabolism.

Intestinal microbiota and BA metabolism are mutually linked, enteric bacterial enzymes shape BA pool size and composition by mediating deconjugation and $7 \alpha$-dehydroxylation of primary BAs (27). Liver cells synthesize primary BAs from cholesterol, mainly consisting of CA and CDCA in human, CA, $\alpha-/ \beta-M C A$ in rodent and CA, HCA, and CDCA in pigs, and these BAs were conjugated with either glycine (G-BAs) or taurine (T-BAs) via their $\mathrm{N}$-acyl amidate to increased solubility before secretion into intestine (30). Bile salt deconjugation is carried out by BSH, expressed in Lactobacillus, Bifidobacterium, Clostridium, and Bacteroides $(9,31)$. The genus Lactobacillus and its BSH activity could result in deconjugation of conjugated BAs (32). The conjugated BAs are very soluble, and most of them are reabsorbed in the ileum into enterohepatic circulation. In our study, $L$. delbrueckii administration obviously increased the ileal Lactobacillus abundance, indicating that ileal bacterial BA deconjugation might enhance. Interestingly, we found ileal concentrations of GCDCA, GLCA, and unconjugated BAs were decreased in the Con $+\mathrm{LD}$ group. Bacterial deconjugation of TBA or G-BA can reduce serum cholesterol levels via amplifying the formation of new bile salts needed to replace those that 
A

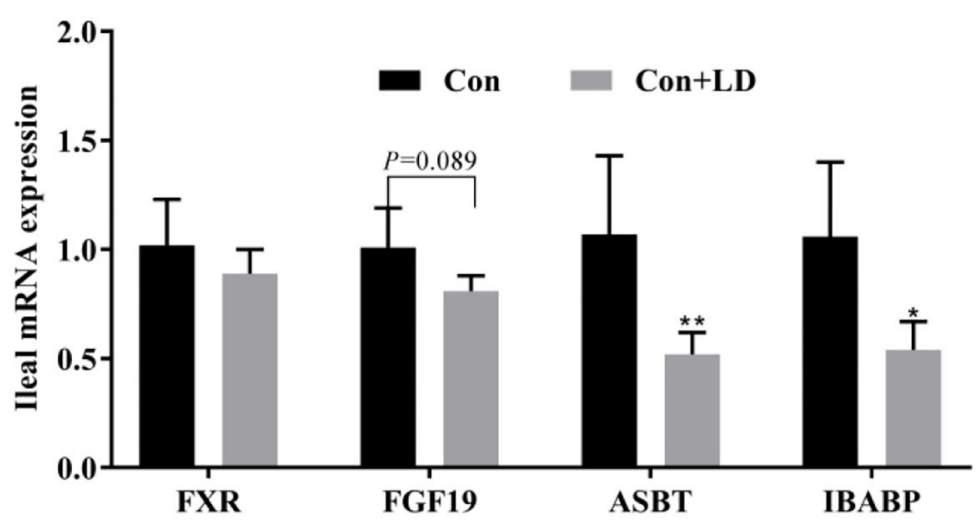

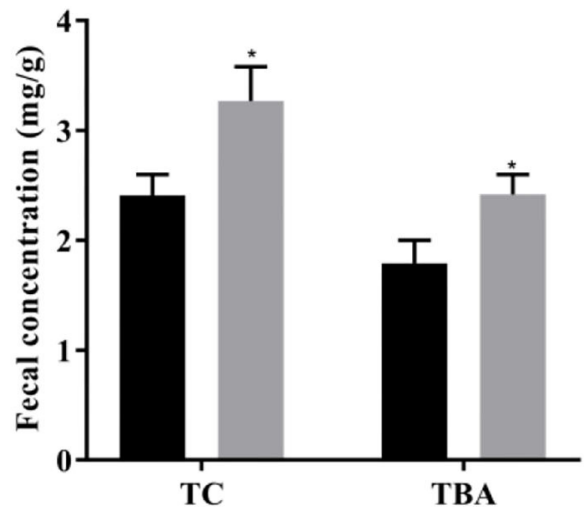

C
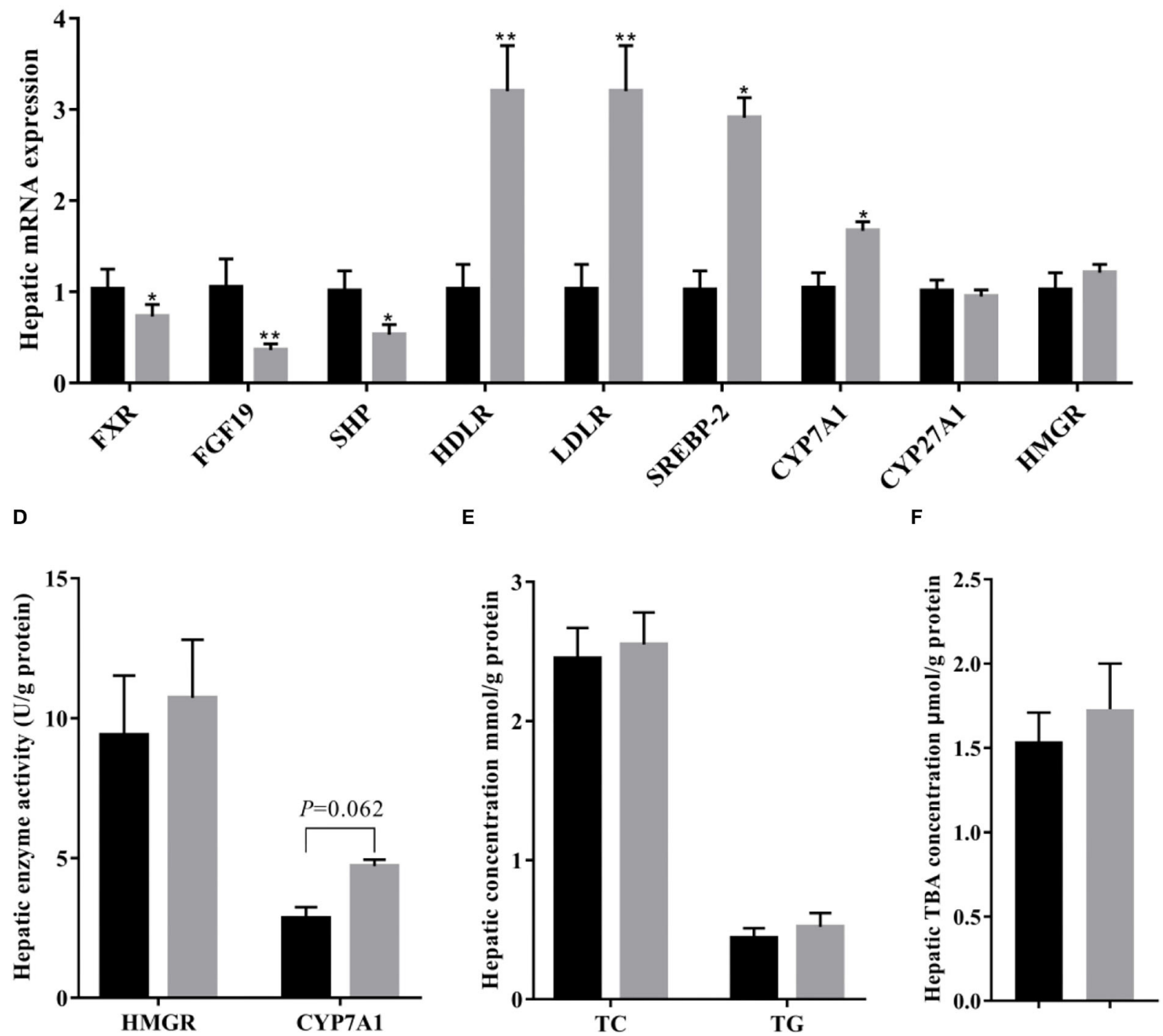

FIGURE 5 | Bile acid and cholesterol transport, biosynthesis, and excretion of growing-finishing pigs. Bile acid receptors and transporters along the ileum (A). Fecal TC and TBA excretion (B). Bile acid metabolism-related genes in the liver (C). Hepatic enzyme activity related to cholesterol and bile acid synthesis (D). Hepatic TC and TG (E) and TBA (F) concentrations ( $\left.{ }^{\star} P<0.05 ;{ }^{* \star} P<0.01\right)$. 


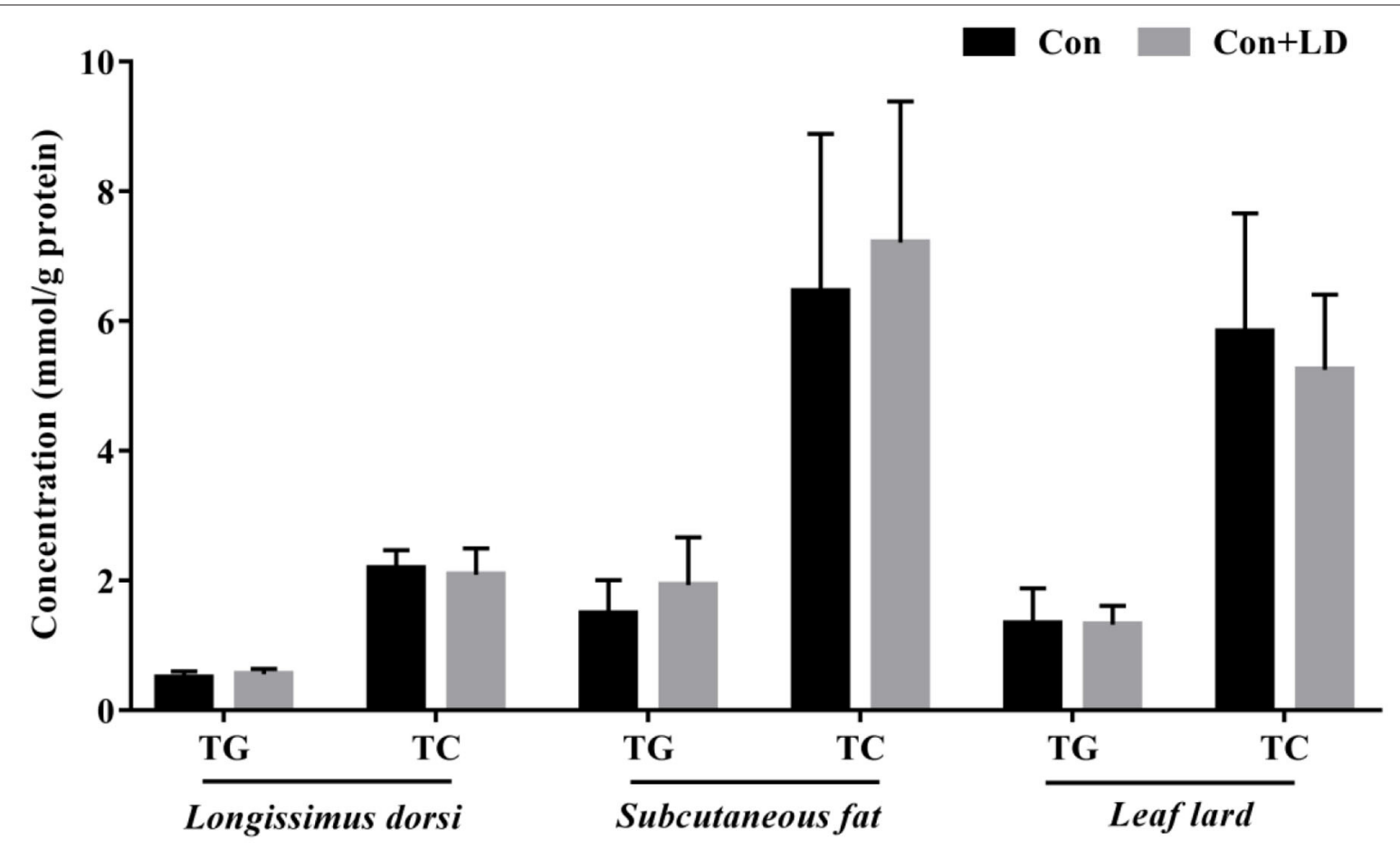

FIGURE 6 | Concentrations of TG and TC in the selected tissues of growing-finishing pigs.

have escaped enterohepatic cycle (26). Therefore, the potential mechanism of cholesterol reduction in L. delbrueckii might be the conversion of bile salt to free BA by improving ileal Lactobacillus abundance with BSH activity and interfered with BAs enterohepatic circulation.

In the intestine, bile salts play an important role in emulsifying lipids. Ileum is confirmed as the major site for BA reabsorption, and the highest expression of BA transporters and FGF19 was observed along the intestinal segment (10). Intestinal BA transporters play a vital role on the $\mathrm{BA}$ reabsorption process. $\mathrm{ASBT}$ and $\mathrm{IBABP}$ are important $\mathrm{BA}$ transporters engaging in $\mathrm{BA}$ active or passive transport. ASBT imports luminal BAs to the enterocytes where the BAs bind to IBABP and are transferred to the basement surface and then enter into portal vein with the help of MRP3 and OST $\alpha /$ OST $\beta$ transporters in the basolateral membrane (10). In the present study, ileal expression of $A S B T$ and $I B A B P$ in $L$. delbrueckii-treated pigs was markedly downregulated, indicating that less ileal BAs were reabsorbed after $L$. delbrueckii consumption.

The liver is the center of the synthesis and metabolism of cholesterol and BAs. Cholesterol de novo synthesis begins with acetyl-CoA, and HMGR is the rate-limiting enzyme responsible for catalyzing the conversion of HMG-CoA into mevalonic acid. Our results showed that administration of $L$. delbrueckii did not affect HMGR activity and mRNA expression, but upregulated hepatic SREBP2, $L D L R$, and HDLR expression. SREBP2 is a key nuclear transcription factor for regulating $L D L R$ and $H M G R$ target genes in charge of extrahepatic cholesterol uptake and endogenous cholesterol biosynthesis (33). Hepatic HDLR and
LDLR are responsible for combining blood HDL-C and LDL-C to remove cholesterol, respectively. HDL-C carries cholesterol from peripheral tissues to liver; conversely, LDL-C transports hepatic cholesterol to peripheral tissues. Our observations implied $L$. delbrueckii treatment had no influence on hepatic cholesterol synthesis, but it might change its metabolism via hepatic clearance. The conversion of cholesterol to BAs is the main way to eliminate hepatic cholesterol, and CYP7A1 is the ratelimiting enzymes in the pathway (4). In the present study, hepatic CYP7A1 expression was increased, and CYP7A1 activity also tended to rise in the Con $+\mathrm{LD}$ group, indicating that dietary L. delbrueckii might lower cholesterol via enhancing BAs biosynthesis.

Hepatic BA synthesis is negatively regulated by FXR signaling and FGF19 signaling (34). Ileal FXR activation contributes to FGF19 production, and then FGF19 translocates to the liver via hepatic portal vein where it binds to the FGFR4/ $\beta$-Klotho complex and inhibits CYP7A1 expression $(9,15)$. CYP7A1 is the rate-limiting enzyme in classic pathway for hepatic BA synthesis. Our results showed that ileal FGF19 expression and hepatic FXR and FGF19 expression were downregulated, but CYP7A1 expression and CYP7A1 activity were increased by $L$. delbrueckii treatment, suggesting that this strain increased the conversion of cholesterol to BAs in the liver via suppressing FXRFGF19 signaling and improving CYP7A1 activity. Additionally, reduction of hepatic FXR and SHP expression could also explain the increased CYP7A1 activity, because hepatic FXR stimulation resulted in SHP expression upregulation to inhabit CYP7A1 and CYP8B1 activity (3). 


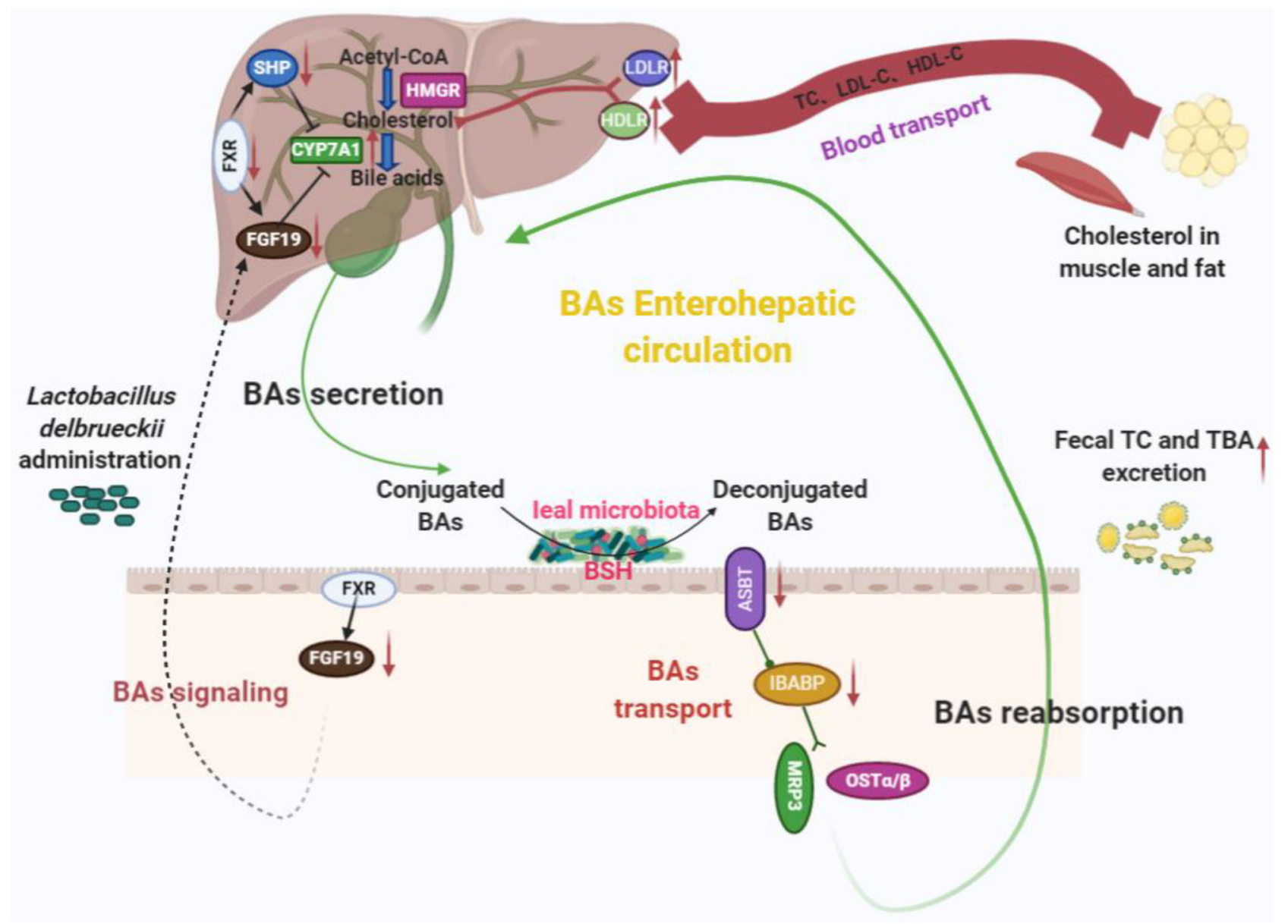

FIGURE 7 | Potential cholesterol-lowering mechanisms of Lactobacillus delbrueckii-fed pigs. Ileal microbiota modification (mainly increased ileal Lactobacillus abundance) with $L$. delbrueckii administration led to bile salts deconjugation by BSH activity and facilitated fecal TBA and TC excretion. Meanwhile, less deconjugated BAs are reabsorbed into enterohepatic circulation and downregulate BA transporter expression (ASBT and IBABP) and promote BA synthesis via increasing the conversion of cholesterol to BA with the help of CYP7A1, a rate-limiting enzyme, in the liver. Additionally, ileal BA deconjugation by microbiota alteration affects BA signaling (FXR-FGF19 axis) to regulated BA synthesis. Enhancement of BA synthesis using circulating cholesterol (blood transport) to restore the bile acid pool.

The homeostasis of BAs pool is maintained by enterohepatic cycle. Quantitative determination of BAs profiles via UPLC-MS analysis could reflect the enterohepatic circulation of BAs (35, 36). In our study, we observed great changes in BA composition of serum, ileal digesta, and liver, which might ascribe ileal microbiota modification with $L$. delbrueckii. Deconjugation of ileal bile salts causes less BAs to enter portal vein and return to liver, and unabsorbed BAs flow into hindgut and are excreted along with feces. Fecal BA excretion is almost equal to the hepatic synthesized BAs under the normal physiological condition (4, 37). Enhancement of BA synthesis using circulating cholesterol to restore the BA pool is an important manner for reduction of serum cholesterol $(38,39)$. In our study, dietary L. delbrueckii accelerated fecal TC and TBA output of pigs, which was closely associated to the decrease in serum TC and LDL-C. Reduction of serum cholesterol might lower cholesterol deposition in tissues; however, we found no alterations in TG and TC contents in longissimus dorsi, subcutaneous fat, and leaf lard, which implied that short-term L. delbrueckii treatment could not change tissue cholesterol deposition of growing-finishing pigs.

\section{CONCLUSIONS}

Ileal microbiota modification induced by $L$. delbrueckii enhances BA deconjugation and fecal excretion in growing-finishing pigs. These events involved changes in ileal BA reabsorption, repression of the enterohepatic FXR-FGF19 axis, and increased hepatic BA neosynthesis (Figure 7).

\section{DATA AVAILABILITY STATEMENT}

The datasets presented in this study can be found in online repositories. The name of the repository and accession number are SRA and PRJNA670289, respectively. 


\section{ETHICS STATEMENT}

The animal study was reviewed and approved by the Animal Ethics Committee of Hunan Agricultural University. Written informed consent was obtained from the owners for the participation of their animals in this study.

\section{AUTHOR CONTRIBUTIONS}

$\mathrm{GH}, \mathrm{RL}$, and $\mathrm{XH}$ design the experiment. GH, RL, YY, and LW conducted the animal experiments. GH and $\mathrm{RL}$ wrote and revised the manuscript. $\mathrm{XH}, \mathrm{RL}$, and YY offered the experimental reagents and materials. $\mathrm{GH}, \mathrm{RL}$, and WP did experimental analysis, collected, and analyzed the data. GH and RL preparedthe figures and edited the manuscript. All authors reviewed the manuscript.

\section{REFERENCES}

1. Oner O, Aslim B, Aydas SB. Mechanisms of cholesterol-lowering effects of lactobacilli and bifidobacteria strains as potential probiotics with their bsh gene analysis. J Mol Microb Biotech. (2014) 24:12-8. doi: 10.1159/000354316

2. Thushara RM, Gangadaran S, Solati Z, Moghadasian MH. Cardiovascular benefits of probiotics: a review of experimental and clinical studies. Food Funct. (2016) 7:632-42. doi: 10.1039/C5FO01190F

3. Ishimwe N, Daliri EB, Lee BH, Fang F, Du GC. The perspective on cholesterollowering mechanisms of probiotics. Mol Nutr Food Res. (2015) 59:94-105. doi: 10.1002/mnfr.201400548

4. Wang G, Huang W, Xia YJ, Xiong Z, Ai L. Cholesterol-lowering potentials of Lactobacillus strain overexpression of bile salt hydrolase on high cholesterol diet-induced hypercholesterolemic mice. Food Funct. (2019) 10:1684-95. doi: 10.1039/C8FO02181C

5. De Smet I, De Boever P, Verstraete W. Cholesterol lowering in pigs through enhanced bacterial bile salt hydrolase activity. Brit J Nutr. (1998) 79:185-94. doi: 10.1079/BJN19980030

6. Chiu CW, Kao TH, Chen BH. An improved analytical method for determination of cholesterol oxidation products in meat and animal fat by QuEChERS coupled with gas chromatography-mass spectrometry. J Agric Food Chem. (2018) 66:3561-71. doi: 10.1021/acs.jafc.8b00250

7. Dorado M, Gomez EMM, Jimenez-Colmenero F, Masoud TA. Cholesterol and fat contents of Spanish commercial pork cuts. Meat Sci. (1999) 51:321-3. doi: 10.1016/S0309-1740(98)00126-0

8. He YN, Yang XG, Xia J, Zhao LY, Yang YX. Consumption of meat and dairy products in China: a review. Proc Nutr Soc. (2016) 75:385-91. doi: 10.1017/S0029665116000641

9. Sun LL, Pang YY, Wang XM, Wu Q, Liu HY, Liu B, et al. Ablation of gut microbiota alleviates obesity-induced hepatic steatosis and glucose intolerance by modulating bile acid metabolism in hamsters. Acta Pharm Sin B. (2019) 9:702-10. doi: 10.1016/j.apsb.2019.02.004

10. Fang V, Zhang L, Meng Q, Wu W, Lee YK, Xie J, et al. Effects of dietary pectin on the profile and transport of intestinal bile acids in young pigs. J Anim Sci. (2018) 96:4743-54. doi: 10.1093/jas/sky327

11. Lepercq P, Relano P, Cayuela C, Juste C. Bifidobacterium animalis strain DN173010 hydrolyses bile salts in the gastrointestinal tract of pigs. Scand J Gastroentero. (2004) 39:1266-71. doi: 10.1080/00365520410003515

12. Jones ML, Tomaro-Duchesneau C, Martoni CJ, Prakash S. Cholesterol lowering with bile salt hydrolase-active probiotic bacteria, mechanism of action, clinical evidence, and future direction for heart health applications. Expert Opin Biol Ther. (2013) 13:631-42. doi: 10.1517/14712598.2013.758706

\section{FUNDING}

This research was supported by the National Natural Science Foundation of China (Grant nos. 31772617 and 31802074), the Hunan Excellent Post-doctoral Innovative Talents Project (Grant no. 2020RC2063), the Hunan postgraduate research and innovation project (Grant nos. CX2017B346 and CX2018B399), and the School-enterprise cooperation project (E0490205 and E0490207).

\section{ACKNOWLEDGMENTS}

We would like to thank the hardwork of all the project participants.

\section{SUPPLEMENTARY MATERIAL}

The Supplementary Material for this article can be found online at: https://www.frontiersin.org/articles/10.3389/fnut.2020. 617676/full\#supplementary-material
13. Fang W, Wen XB, Meng QS, Wu WD, Everaert N, Xie JJ, et al. Alteration in bile acids profile in large white pigs during chronic heat exposure. $J$ Therm Biol. (2019) 84:375-83. doi: 10.1016/j.jtherbio.2019.07.027

14. Guo CF, Zhang S, Yuan YH, Li JY, Yue TL. Bile salt hydrolase and Slayer protein are the key factors affecting the hypocholesterolemic activity of Lactobacillus casei-fermented milk in hamsters. Mol Nutr Food Res. (2018) 62:e1800728. doi: 10.1002/mnfr.201800728

15. Yao L, Seaton SC, Ndousse-Fetter S, Adhikari AA, DiBenedetto N, Mina AI, et al. A selective gut bacterial bile salt hydrolase alters host metabolism. Elife. (2018) 7:e37182. doi: 10.7554/eLife.37182

16. Li R, Hou GH, Wei LK, Peng W, Pan J, Huang XG. Effects of Lactobacillus delbrueckii on serum biochemical parameters, related genes mRNA expression of cholesterol metabolism and fat deposition in finishing pigs. Chinese J Anim Nutri. (2017) Chin J Anim Nutr. (2017) 29:3184-92. doi: 10.3969/j.issn.1006-267x.2017.09.027

17. NRC. Nutrient Requirements of Swine. 11th Edn. Washington, DC: Natl. Acad. Press (2012).

18. Jayashree S, Pooja S, Pushpanathan M, Rajendhran J, Gunasekaran P. Identification and characterization of bile salt hydrolase genes from the genome of Lactobacillus fermentum MTCC 8711. Appl Biochem Biotechnol. (2014) 174:855-66. doi: 10.1007/s12010-014-1118-5

19. Guo XH, Kim JM, Nam HM, Park SY, Kim JM. Screening lactic acid bacteria from swine origins for multistrain probiotics based on in vitro functional properties. Anaerobe. (2010) 16:321-6. doi: 10.1016/j.anaerobe.2010.03.006

20. Li R, Chang L, Hou GF, Song ZH, Fan ZY, He X, et al. Colonic microbiota and metabolites response to different dietary protein sources in a piglet model. Front Nutr. (2019) 6:151. doi: 10.3389/fnut.2019.00151

21. Li R, Hou GF, Jiang XD, Song ZH, Fan ZY, Hou DX, et al. Different dietary protein sources in low protein diets regulate colonic microbiota and barrier function in a piglet model. Food Funct. (2019) 10:6417-28. doi: 10.1039/C9FO01154D

22. Choi SB, Lew LC, Yeo SK, Nair Parvathy S, Liong MT. Probiotics and the BSHrelated cholesterol lowering mechanism: a Jekyll and Hyde scenario. Crit Rev Biotechnol. (2015) 35:392-401.

23. Xie N, Cui Y, Yin YN, Zhao X, Yang JW, Wang ZG, et al. Effects of two Lactobacillus strains on lipid metabolism and intestinal microflora in rats fed a high-cholesterol diet. BMC Complem Altern Med. (2011) 11:53. doi: 10.1186/1472-6882-11-53

24. Ding WR, Shi C, Chen M, Zhou JW, Long RJ, Guo XS. Screening for lactic acid bacteria in traditional fermented Tibetan yak milk and evaluating their probiotic and cholesterol-lowering potentials in rats fed a high-cholesterol diet. J Funct Foods. (2017) 32:324-32. doi: 10.1016/j.jff.2017.03.021 
25. Li C, Nie SP, Ding Q, Zhu KX, Wang ZJ, Xiong T, et al. Cholesterol-lowering effect of Lactobacillus plantarum NCU116 in a hyperlipidaemic rat model. $J$ Funct Foods. (2014) 8:340-7. doi: 10.1016/j.jff.2014.03.031

26. Wang CY, Wu SC, Ng CC, Shyu YT. Effect of Lactobacillus-fermented adlaybased milk on lipid metabolism of hamsters fed cholesterol-enriched diet. Food Res Int. (2010) 43:819-24. doi: 10.1016/j.foodres.2009.11.020

27. Degirolamo C, Rainaldi S, Bovenga F, Murzilli S, Moschetta A. Microbiota modification with probiotics induces hepatic bile acid synthesis via downregulation of the Fxr-Fgf15 axis in mice. Cell Rep. (2014) 7:12-8. doi: 10.1016/j.celrep.2014.02.032

28. Singh TP, Malik RK, Katkamwar SG, Kaur G. Hypocholesterolemic effects of Lactobacillus reuteri LR6 in rats fed on high-cholesterol diet. Int J Food Sci Nutr. (2015) 66:71-5. doi: 10.3109/09637486.2014.953450

29. Alonso L, Fontecha J, Cuesta P. Combined effect of Lactobacillus acidophilus and $\beta$-cyclodextrin on serum cholesterol in pigs. Br J Nutr. (2016) 115:1-5. doi: $10.1017 /$ S0007114515003736

30. Wang $\mathrm{P}$, Lin S, Wu D, Fang ZF. Recent progress in nutrition physiology role and metabolism regulation of bile acids. Chinese J Anim Nutri. (2019) 31:49-58. doi: 10.3969/j.issn.1006-267x.2019.05.005

31. Han K, Bose S, Wang JH, Lim SK, Chin YW, Kim YM, et al. In vivo therapeutic effect of combination treatment with metformin and Scutellaria baicalensis on maintaining bile acid homeostasis. PLoS ONE. (2017) 12:e0182467. doi: 10.1371/journal.pone.0182467

32. Tian Y, Cai J, Gui W, Nichols RG, Koo I, Zhang J, et al. Berberine directly affects the gut microbiota to promote intestinal farnesoid $\mathrm{X}$ receptor activation. Drug Metab Dispos. (2019) 47:86-93. doi: 10.1124/dmd.118.083691

33. Luo J, Yang HY, Song BL. Mechanisms and regulation of cholesterol homeostasis. Nat Rev Mol Cell Bio. (2020) 21:225-45. doi: 10.1038/s41580-019-0190-7

34. Kim B, Park KY, Ji Y, Park S, Holzapfel W, Hyun CK. Protective effects of Lactobacillus rhamnosus GG against dyslipidemia in high-fat diet-induced obese mice. Biochem Biophys Res Commun. (2016) 473:530-6. doi: 10.1016/j.bbrc.2016.03.107

35. Li Y, Ma J, Yao K, Su W, Tan B, Wu X, et al. Circadian rhythms and obesity: Timekeeping governs lipid metabolism. J Pineal Res. (2020) 69:e12682. doi: 10.1111/jpi.12682

36. Yin J, Li YY, Han H, Ma J, Liu G, Wu X, et al. Administration of exogenous melatonin improves the diurnal rhythms of the gut microbiota in mice fed a high-fat diet. mSystems. (2020) 5:e0002-20. doi: 10.1128/mSystems.00 002-20

37. Guo CF, Li JY. Hypocholesterolaemic action of Lactobacillus casei F0822 in rats fed a cholesterol-enriched diet. Int Dairy J. (2013) 32:144-9. doi: 10.1016/j.idairyj.2013.04.001

38. Thandapilly SJ, Ndou SP, Yanan W, Nyachoti CM, Ames NP. Barley $\beta$ glucan increases fecal bile acid excretion and short chain fatty acid levels in mildly hypercholesterolemic individuals. Food Funct. (2018) 9:3092-6. doi: 10.1039/C8FO00157J

39. Yin J, Li YY, Han H, Chen S, Gao J, Liu G, et al. Melatonin reprogramming of gut microbiota improves lipid dysmetabolism in high-fat diet-fed mice. $J$ Pineal Res. (2018) 65:e12524. doi: 10.1111/jpi.12524

Conflict of Interest: The authors declare that the research was conducted in the absence of any commercial or financial relationships that could be construed as a potential conflict of interest.

Copyright (c) $2020 \mathrm{Hou}$, Peng, Wei, Li, Yuan, Huang and Yin. This is an open-access article distributed under the terms of the Creative Commons Attribution License (CC $B Y)$. The use, distribution or reproduction in other forums is permitted, provided the original author(s) and the copyright owner(s) are credited and that the original publication in this journal is cited, in accordance with accepted academic practice. No use, distribution or reproduction is permitted which does not comply with these terms. 